\title{
RANCANG BANGUN APLIKASI PEMBELAJARAN PENGENALAN KOSAKATA BAHASA INGGRIS BERBASIS TEKNOLOGI AUGMENTED REALITY (STUDI KASUS PADA KOSAKATA PERALATAN MEBEL)
}

\author{
Muhammad Sholeh ${ }^{*}$, Suraya ${ }^{2}$, Markus Andika ${ }^{3}$ \\ ${ }_{1,2,3}$ Prodi Informatika- Institut Sains \& Teknologi AKPRIND Yogyakarta \\ "muhash@akprind.ac.id
}

\begin{abstract}
ABSTRAK
Teknologi Augmented Reality (AR) dapat digunakan sebagai media pembelajaran yang menarik bagi anak-anak. Dengan AR tampilan benda yang ditampilkan dapat disajikan dalam bentuk 3D. Perpaduan antara AR dengan proses pembelajaran menjadi pengalaman tersendiri bagi anak-anak. Penggunaan smart phone saat ini sudah menjadi sesuatu yang biasa sehingga agar anak-anak dapat menggunakan smart phone sesuai usia nya, peru adanya media pembelajaran yang berbasis teknologi informasi. Penelitian bertujuan untuk memberikan alternatif dalam proses pembelajaran kosa kata bahasa Inggris terutama kosa kata peralatan rumah tangga. Metode penelitian menggunakan metode pengembangan rapid application development (RAD). metode ini dipilih karena lebih luwes dalam proses implementasi. Metode RAD menekankan pada proses pengembangan dan pembuatan aplikasi berdasarkan pembuatan prototype, iterasi, dan umpan balik yang berulang-ulang. Dengan Metode RAD, aplikasi yang dibuat bisa dikembangkan dan diperbaiki dengan cepat. Proses analisis dilakukan dengan membuat model alur sistem dengan menggunakan unified modelling language Aplikasi dibangun dengan menggunakan Unity 3D dan Vuforia. Aplikasi diuji dengan melakukan pengujian fungsional dan pengujian posisi dalam proses memindai posisi marker. Berdasarkan hasil pengujian, pengujian fungsional sudah sesuai dengan skenario dan pengujian posisi marker, posisi marker masih bisa dideteksi pada posisi yang beraneka ragam. Aplikasi tetap dapat menampilkan gambar 3D, selama proses deteksi marker berhasil . Hasil penelitian berupa aplikasi berbasis android yang dapat memperkenalkan peralatan mebel dalam bentuk gambar 3D dan dilengkapi dengan kosa kata bahasa Indonesia dan bahasa Inggris. Proses menampilkan gambar 3D yang dilengkapi dengan kosa kata dilakukan dengan mengarahkan kamera smart phone pada marker (gambar) yang sudah tersedia. Kumpulan marker pembelajaran benda ini dikemas dalam bentuk brosur. Hasil proses pindai pada marker, aplikasi akan menampilkan gambar dalam bentuk 3D.
\end{abstract}

Kata kunci : Augmented Reality. Media pembelajaran, marker, brosur

\section{ABSTRACT}

Augmented Reality (AR) technology can be used as an interesting learning medium for children. With AR, the displayed objects can be presented in $3 D$. The combination of $A R$ with the learning process is a separate experience for children. The use of smart phones has now become commonplace so that children can use smart phones according to their age, there is a need for learning media based on information technology. This study aims to provide an alternative in the process of learning English vocabulary, especially vocabulary for household appliances. The 
research method uses the rapid application development (RAD) method. This method was chosen because it is more flexible in the implementation process. The $R A D$ method emphasizes the process of developing and making applications based on prototyping, iteration, and repeated feedback. With the RAD method, applications created can be developed and repaired quickly. The analysis process is carried out by creating a system flow model using a unified modeling language. The application is built using Unity $3 D$ and Vuforia. The application is tested by performing functional testing and position testing in the process of scanning the marker position. Based on the test results, functional testing is in accordance with the scenario and testing the marker position, the marker position can still be detected in various positions. The application can still display $3 D$ images, as long as the marker detection process is successful. The result of the research is an android-based application that can introduce furniture equipment in the form of $3 D$ images and is equipped with Indonesian and English vocabulary. The process of displaying $3 D$ images equipped with vocabulary is done by pointing the smart phone camera at the marker (image) that is already available. This collection of learning object markers is packaged in the form of a brochure. The results of the scan process on the marker, the application will display the image in $3 D$.

Keywords: Augmented Reality. Learning media, markers, brochures, furniture

\section{PENDAHULUAN}

Media yang digunakan dalam proses pembelajaran terutama yang diperuntukkan pada anak-anak harus dikemas menarik. Di era teknologi informasi dan penggunaan smart phone yang sudah menjadi kebutuhan vital saat ini, perlu adanya nya inovasi dalam media pembelajaran. Penggunaan teknologi informasi dalam media pembelajaran memberikan daya tarik dan pengalaman tersendiri bagi anak-anak. Media pembelajaran yang dikemas teknologi informasi mempunyai nilai yang berbeda dengan pembelajaran yang selama ini dikemas dalam bentuk buku. Penggunaan alat bantu yang bersifat interaktif dapat menjadi salah satu media yang digunakan dalam pembelajaran dan dapat memberikan penjelasan yang lebih detail. Dengan media ini diharapkan dapat meningkatkan daya nalar, minat serta perhatian anak-anak. Penggunaan teknologi informasi dan komunikasi (TIK) sebagai media yang digunakan dalam proses pembelajaran dapat digunakan dengan pemanfaatan perangkat komputer yang ada di sekolahan atau menggunakan peralatan smart phone. Penggunaan TIK dalam sebagai media belajar dapat berupa gabungan antara materi dengan video atau dalam bentuk animasi. Penggunaan teknologi informasi dalam pengembangan media belajar dapat berupa gabungan antara materi dengan video atau dalam bentuk animasi. Penggunaan teknologi informasi ini dapat memberikan dampak yang bagus dalam proses pembelajaran dan penggunaan media pembelajaran yang menggunakan TIK dapat meningkatkan motivasi dan minat siswa dalam mempelajari materi . (Adiko, 2019),(Candra, 2020), (Mardhatillah, 2016).

Pembelajaran berbasis TIK merupakan upaya dalam menggunakan perkembangan TIK 
Prosiding The 1st National Conference on Applied Business, Education, \& Technology (NCABET)"

Unversitas Bina Bangsa 2021

DOI Article : 10.46306/ncabet.v1i1.6

dalam proses mendukung pembelajaran dan dapat dimanfaatkan sebagai media alternatif dalam proses pembelajaran dan tidak menjadi media pembelajaran utama, sehingga teknologi khususnya TIK dapat membantu manusia dalam menyelesaikan berbagai kegiatan, termasuk dalam proses pembelajaran. (Azhariadi et al., 2019). Pengembangan media pembelajaran berbasis TIK dapat dikemas dengan berbagai ragam inovasi. Media pembelajaran dapat dikemas dalam bentuk video (Ponza et al., 2018),(Fadhli, 2015), animasi (Widiyasanti et al., 2018), (Sunami \& Aslam, 2021), dan komik (Andriyani \& Kusmariyatni, 2019), (Ambaryani \& Airlanda, 2017), (Eva et al., 2020). Alternatif lain dalam pembuatan media pembelajaran adalah dengan menggunakan augmented reality (Sholeh et al., 2021),(Mukti, 2019),(Oktaviani et al., 2020)

Seiring perkembangan teknologi khususnya TIK, media yang dapat digunakan dalam pengembangan media pembelajaran tidak hanya berbasis video atau animasi. Perkembangan saat ini dalam pembuatan media pembelajaran dapat menggunakan Augmented Reality (AR). AR merupakan teknologi yang didesain dengan menggabungkan teknologi berbasis objek 2 dimensi atau 3 dimensi. Teknologi 2D atau 3D ini dibuat dengan menggunakan aplikasi dan menghasilkan aplikasi yang mirip dengan dunia nyata. Objek dalam bentuk 3D yang ditampilkan dalam aplikasi AR dapat membantu pengguna dalam mempelajari suatu objek (Ismayani, 2020), (Grubert, 2013). Penggunaan AR sudah banyak digunakan diberbagai aplikasi, mulai dari game sampai dunia pendidikan dan pembelajaran. Dalam mengembangkan bahan ajar dengan AR, ada beberapa aplikasi gratis seperti Unity dan Vuforia yang dapat digunakan dalam proses pengembangan bahan ajar. (Pamoedji et al., 2017), (Adam Sinicky, 2019).

Dengan latar belakang di atas, penelitian dilakukan dengan membuat rancang bangun media pembelajaran yah dapat digunakan dalam mempelajari kosakata bahasa Inggris. Batasan kosa kata adalah kosa kata pengenalan peralatan rumah tangga (furniture). Hasil aplikasi menampilkan benda furniture dalam bentul 3D yang dilengkapi dengan narasi nama alat baik dalam kata bahasa Inggris maupun dalam kata bahasa Indonesia . Agar dapat menggunakan aplikasi tersebut, pengguna harus mempunyai brosur yang berisi gambar (marker) yang digunakan untuk memindai. Hasil pindaian akan menampilkan AR dalam bentuk 3D.

\section{METODE PENELITIAN}

Penelitian dilakukan dengan melakukan rancang bangun aplikasi yang dapat dugunakan sebagai media pembelajaran pengenalan kosa kata bahasa Inggris khususnya peralatan rumah tangga yang diterapkan dalam AR. Hasil penelitian menghasilkan brosur 
yang digunakan untuk memindai objek dan aplikasi yang dapat digunakan mendeteksi gambar yang ada dalam brosur dengan menggunakan teknologi AR. .

Metode Penelitian yang digunakan menggunakan metode rapid application development (RAD. RAD lebih berfokus pada kecepatan dalam proses pengembangan sistem untuk memenuhi keinginan atau kebutuhan pengguna (Sri Mulyani, 2016). Tahapan metode RAD ada 4 tahapan yaitu proses perencanaan kebutuhan pengguna, melakukan desain sistem, proses pengembangan \& pengumpulan umpan balik dan melakukan proses implementasi (Rahmawati, 2020),(Irnawati \& Listianto, 2018). Gambar 1, merupakan gambaran proses dalam RAD.

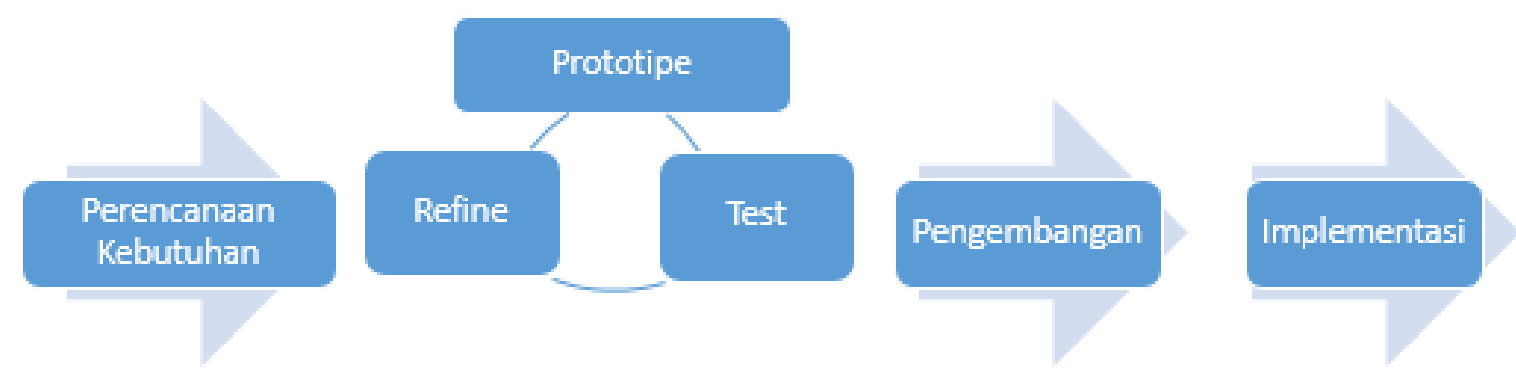

Gambar 1 Metode rapid application development

\section{HASIL DAN PEMBAHASAN}

\section{A. Model Unified Modelling Language (UML)}

Pemodelan merupakan tahapan dalam proses merancang suatu sistem yang dilakukan sebelum tahap pembuatan aplikasi. Perancangan sistem dilakukan dengan membuat model dari masalah yang ada dalam bentuk diagram UML. Diagram UML yang digunakan adalah diagram use case diagram, activity diagram, sequence diagram.

\section{A.1. Use Case Diagram}

Use case diagram digunakan untuk memberikan gambaran hubungan dari sejumlah external actor dengan use case yang ada pada suatu sistem. Diagram ini mendeskripsikan bagaimana sistem digunakan oleh pengguna. Gambar 2, merupakan hasil rancangan diagram use case. 


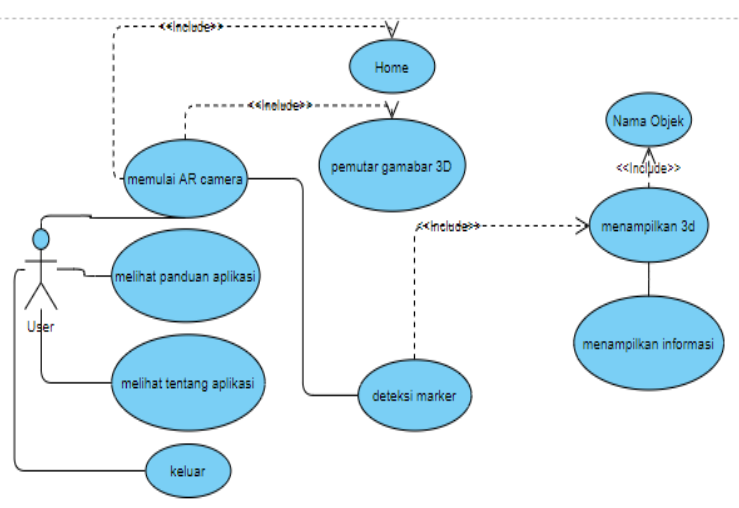

\section{Gambar 2 Use Case Diagram}

Pada Gambar 2 media pembelajaran berbasis AR terdapat satu aktor yang terlibat, yaitu user (pengguna). Pengguna yang dimaksud dalam diagram ini adalah siswa yang menggunakan aplikasi AR. Dari diagram uses case, user dapat melakukan empat proses yaitu : memulai AR kamera, melihat panduan aplikasi, melihat tentang aplikasi, dan keluar aplikasi. Sebelum user menggunakan aplikasi, user harus mengunduh dan memasang aplikasi di smart phone. User tidak perlu login untuk dapat menggunakan aplikasi ini.

\section{A.2. Activity Diagram}

Activity diagram dapat digunakan dalam proses mendeskripsikan prosedural, proses bisnis dan aliran kerja. Diagram ini menunjukkan tahapan dalam pengambilan keputusan dan percabangan. Activity diagram dapat menunjukkan siapa mengerjakan apa. Pada penelitian ini ada tiga activity diagram yaitu memulai AR Kamera, panduan dan tentang aplikasi. Gambar 3 menampilkan Activity diagram



Gambar 3 Activity Diagram AR Kamera

Gambar 3 menggambarkan activity diagram AR Kamera. Activity diagram ini menunjukkan proses bagaimana user membuka aplikasi, masuk ke menu AR Kamera hingga 
user dapat melihat tampilan objek 3D beserta informasi dari objek. User dapat masuk ke aplikasi tanpa harus melewati proses login terlebih dahulu. Setelah menu utama tampil, user dapat memilih tombol AR Kamera untuk memulai pemindaian marker. Marker berupa gambar objek furniture 2D yang menjadi target dan dapat dipindai pada brosur yang telah disediakan. Apabila marker sesuai dengan database, maka marker telah terdeteksi oleh aplikasi, sehingga aplikasi akan menampilkan gambar berupa objek 3D dan terdapat tombol untuk melihat informasi dari objek tersebut. Namun apabila marker tidak sesuai dengan database dan pendeteksian gagal, maka aplikasi akan kembali ke AR Kamera. User dapat melakukan pemindaian ulang.

\section{B. Rancangan Basis Data}

Rancangan basis data merupakan rancangan yang digunakan oleh sistem dalam proses penyimpanan data. Dalam pengembangan AR, basis data digunakan untuk menyimpan marker yang digunakan untuk memindai. Pada penelitian ini proses penyimpanan marker menggunakan database di Vuforia. Rancangan basis data pada aplikasi pengenalan furniture dalam Vuforia disajikan pada Gambar 4

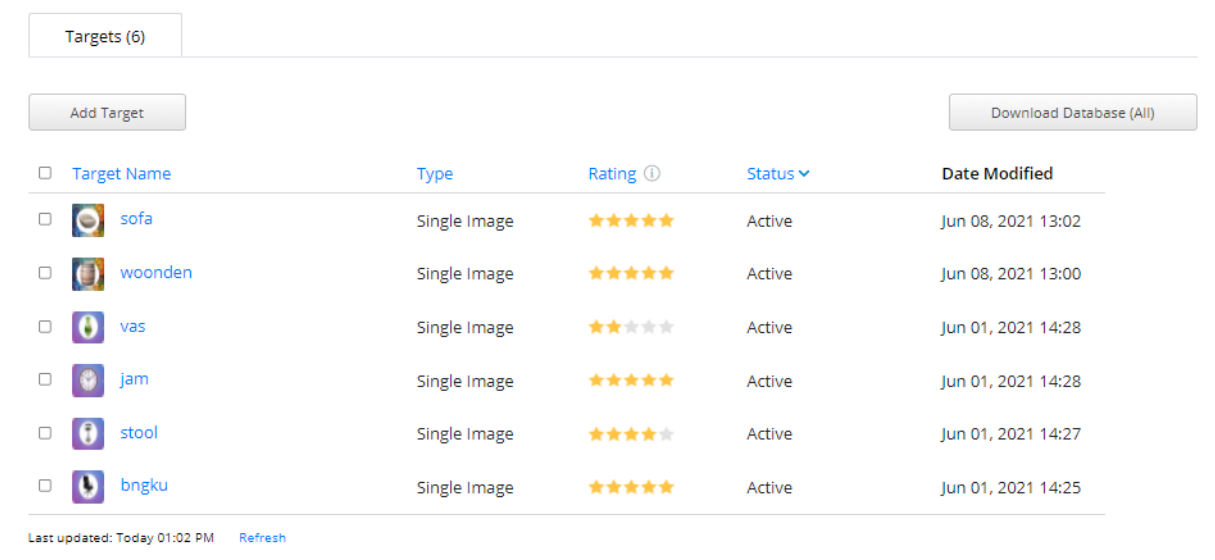

Gambar 4 Rancangan Basis Data

\section{Rancangan Antarmuka Halaman Utama Aplikasi AR}

Halaman utama aplikasi AR menampilkan beberapa menu pilihan yang dapat dipilih dan digunakan oleh pengguna dalam menjalankan aplikasi. Menu yang terdapat pada menu utama yaitu : AR Kamera, Panduan, Tentang, dan Keluar. Rancangan antarmuka menu utama aplikasi pengenalan Furniture disajikan pada Gambar 5 


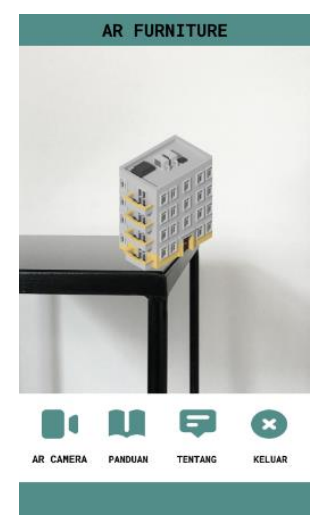

Gambar 5 Rancangan Antarmuka Menu Utama

\section{C.1. Marker}

Marker adalah sebuah penanda yang digunakan sebagai media untuk melakukan pemindaian agar dapat dikenali oleh aplikasi, sehingga objek 3D yang diinginkan dapat ditampilkan oleh aplikasi. Penggunaan marker pada aplikasi ini sebagai bentuk penerapan metode marker based pada penelitian ini. Marker yang digunakan pada aplikasi AR Furniture yaitu foto nyata berbentuk dua dimensi dari masing-masing objek benda. Foto objek ini diambil dari sumber di internet dengan format *.jpg. Hasil penentuan marker yang digunakan pada aplikasi ditunjukkan pada Tabel 1

Tabel 1 Kumpulan Marker Pada Aplikasi

\begin{tabular}{|c|c|}
\hline Gambar Marker & Nama Marker \\
\hline & Bangku \\
\hline & Jam \\
\hline & Sofa \\
\hline & Bangku Stool \\
\hline
\end{tabular}

Hasil desain marker diunggah ke website Vuforia untuk disimpan ke database dan dimasukkan ke perangkat lunak Unity $3 D$ untuk digunakan sebagai lokal database.

\section{C.2. Brosur AR}

Brosur AR berisi marker yang digunakan user selama menggunakan aplikasi $A R$ Furniture. Gambar yang ada pada brosur digunakan untuk memindai marker dan jika proses 
pemindaian berhasil, aplikasi akan menampilkan visualisasi 3D objek Furniture. . Tampilan brosur AR ditunjukkan pada Gambar 6

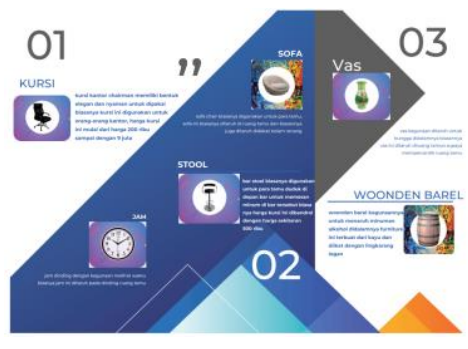

Gambar 6 Tampilan Belakang Brosur AR

\section{C.3. Hasil Deteksi Marker}

Antarmuka deteksi marker pada menu AR Kamera aplikasi AR Furniture. Gambar 7 menampilkan hasil tampilan AR dalam bentuk gambar 3D.
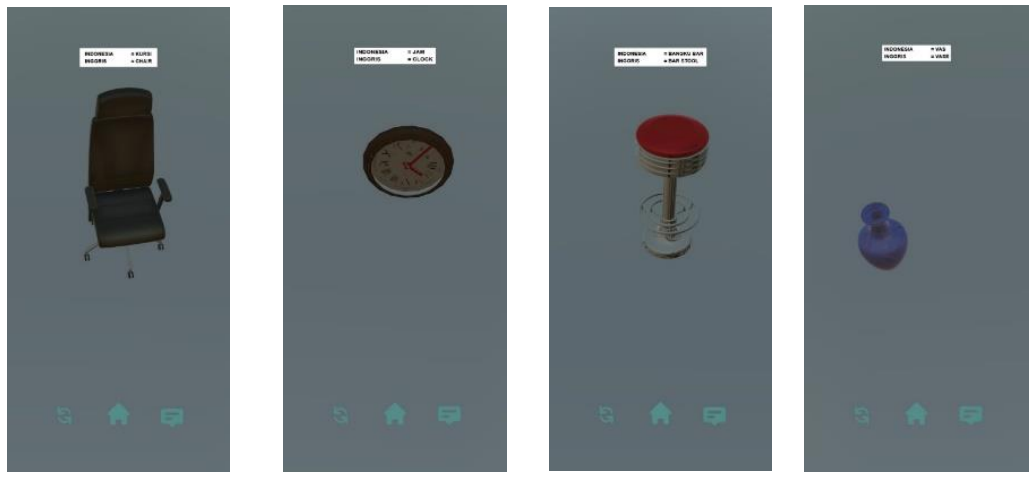

Gambar 7 Tampilan Deteksi Marker gambar AR

\section{Antarmuka Deskripsi Objek}

Halaman deskripsi objek akan tampil ketika user memilih tombol deskripsi pada menu AR kamera saat objek 3D ditampilkan. Halaman ini berupa panel yang berisi informasi tentang objek Furniture sesuai objek yang ditampilkan. Antarmuka deskripsi objek aplikasi $A R$ Furniture disajikan pada Gambar 8. Gambar 8 menampilkan contoh hasil AR dalam bentuk 3D dari beberapa tampilan yang ada dalam aplikasi
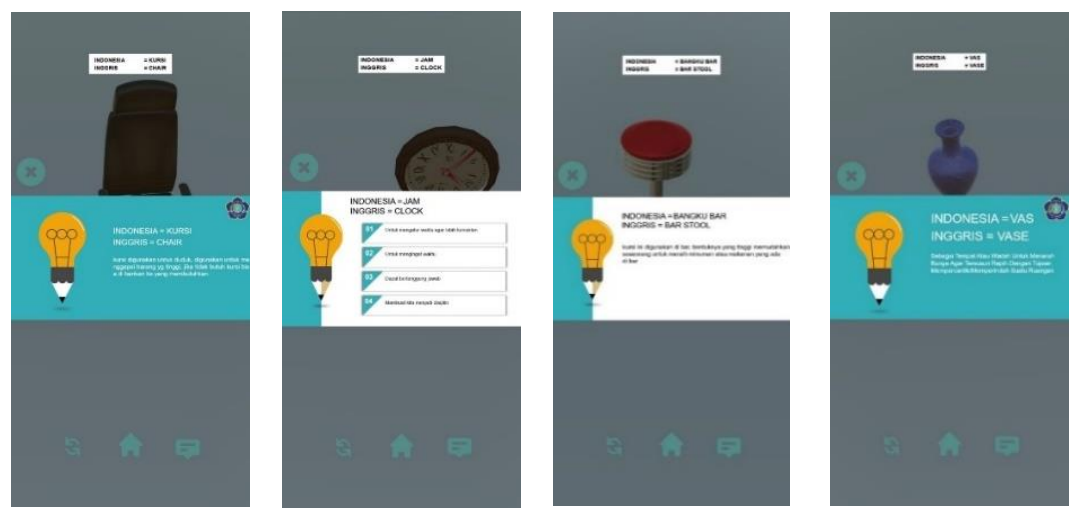

Gambar 8 Tampilan AR dalam bentuk 3D dan narasi deskripsi 
Prosiding The 1st National Conference on Applied Business, Education, \& Technology (NCABET)",

Unversitas Bina Bangsa 2021

DOI Article : 10.46306/ncabet.v1i1.6

\section{E. Pengujian}

Tahapan pengujian aplikasi dilakukan untuk mengetahui sejauh mana aplikasi yang telah dikembangkan sesuai dengan perancangan aplikasi pada tahap sebelumnya atau tidak.

\section{E.1. Pengujian Black Box}

Pengujian black box pada penelitian ini dilakukan pada sisi pengembangan. Metode yang digunakan adalah pengujian black box yang menguji aplikasi secara fungsional, artinya pengujian terhadap fungsi-fungsi pada aplikasi yang dibangun apakah berjalan sesuai tujuan atau tidak.

\section{E.2. Hasil Pengujian Fungsional}

Pengujian aplikasi AR Furniture dilakukan berdasarkan skenario pengujian yang telah ditetapkan. Sehingga didapatkan hasil pengujian yang dijelaskan pada Tabel 2

Tabel 2 Hasil Pengujian Fungsional

\begin{tabular}{|c|l|l|l|l|}
\hline \multirow{2}{*}{ No } & \multirow{2}{*}{ Uji Komponen } & \multicolumn{3}{|c|}{ Skenario Dan Hasil Uji } \\
\cline { 3 - 5 } 1 & Menu ar kamera & $\begin{array}{l}\text { Skenario Uji } \\
\text { kamenan tombol ar }\end{array}$ & $\begin{array}{l}\text { Aplikasi } \\
\text { menghidupkan } \\
\text { kamera untuk proses } \\
\text { pemindaian marker. }\end{array}$ & $\begin{array}{l}\text { Kesimpulan } \\
{[\sqrt{ }] \text { berhasil }[]} \\
\text { tidak berhasil }\end{array}$ \\
\hline 2 & Menu panduan & $\begin{array}{l}\text { Menekan tombol } \\
\text { panduan }\end{array}$ & $\begin{array}{l}\text { Aplikasi menyajikan } \\
\text { informasi panduan } \\
\text { penggunaan aplikasi. }\end{array}$ & $\begin{array}{l}{[\sqrt{ }] \text { berhasil }[]} \\
\text { tidak berhasil }\end{array}$ \\
\hline 3 & Menu tentang & $\begin{array}{l}\text { Menekan tombol } \\
\text { tentang }\end{array}$ & $\begin{array}{l}\text { Aplikasi menyajikan } \\
\text { informasi aplikasi dan } \\
\text { pembuat aplikasi }\end{array}$ & $\begin{array}{l}{[\sqrt{ }] \text { berhasil }[]} \\
\text { tidak berhasil }\end{array}$ \\
\hline 5 & Menu keluar & $\begin{array}{l}\text { Menekan tombol } \\
\text { keluar }\end{array}$ & $\begin{array}{l}\text { Keluar atau selesai dari } \\
\text { penggunaan aplikasi }\end{array}$ & $\begin{array}{l}{[\sqrt{ }] \text { berhasil }[]} \\
\text { tidak berhasil }\end{array}$ \\
\hline 6 & Marker kursi & $\begin{array}{l}\text { Mengarahkan kamera } \\
\text { ar ke marker kursi }\end{array}$ & $\begin{array}{l}\text { Aplikasi menampilkan } \\
\text { objek kursi dalam } \\
\text { bentuk tiga dimensi } \\
\text { beserta tombol putar, } \\
\text { home, dan informasi. }\end{array}$ & $\begin{array}{l}{[\sqrt{ }] \text { berhasil }[]} \\
\text { tidak berhasil }\end{array}$ \\
\hline Marker jam & $\begin{array}{l}\text { Mengarahkan kamera } \\
\text { ar ke marker jam }\end{array}$ & $\begin{array}{l}\text { Apjikasi menampilkan } \\
\text { bentuk tiga dimensi } \\
\text { beserta tombol putar, } \\
\text { home, dan informasi. }\end{array}$ & $\begin{array}{l}{[\sqrt{ }] \text { berhasil }[]} \\
\text { tidak berhasil }\end{array}$ \\
\hline
\end{tabular}




\begin{tabular}{|c|l|l|l|l|}
\hline 7 & $\begin{array}{l}\text { Marker bangku } \\
\text { bar }\end{array}$ & $\begin{array}{l}\text { Mengarahkan kamera } \\
\text { ar ke marker bangku } \\
\text { bar }\end{array}$ & $\begin{array}{l}\text { Aplikasi menampilkan } \\
\text { objek kursi dalam } \\
\text { bentuk tiga dimensi } \\
\text { beserta tombol putar, } \\
\text { home, dan informasi. }\end{array}$ & $\begin{array}{l}{[\sqrt{ }] \text { berhasil }[]} \\
\text { tidak berhasil }\end{array}$ \\
\hline 8 & Marker vas & $\begin{array}{l}\text { Mengarahkan kamera } \\
\text { ar ke marker vas }\end{array}$ & $\begin{array}{l}\text { Aplikasi menampilkan } \\
\text { objek kursi dalam } \\
\text { bentuk tiga dimensi } \\
\text { beserta tombol putar, } \\
\text { home, dan informasi. }\end{array}$ & $\begin{array}{l}{[\sqrt{ }] \text { berhasil }[]} \\
\text { tidak berhasil }\end{array}$ \\
\hline 9 & Marker sofa & $\begin{array}{l}\text { Mengarahkan kamera } \\
\text { ar ke marker sofa }\end{array}$ & $\begin{array}{l}\text { Aplikasi menampilkan } \\
\text { objek kursi dalam } \\
\text { bentuk tiga dimensi } \\
\text { beserta tombol putar, } \\
\text { home, dan informasi. }\end{array}$ & $\begin{array}{l}{[\sqrt{ }] \text { berhasil }[]} \\
\text { tidak berhasil }\end{array}$ \\
\hline 10 & $\begin{array}{l}\text { Marker wooden } \\
\text { barel }\end{array}$ & $\begin{array}{l}\text { Mengarahkan kamera } \\
\text { ar ke marker wooden } \\
\text { barel }\end{array}$ & $\begin{array}{l}\text { Aplikasi menampilkan } \\
\text { objek kursi dalam } \\
\text { bentuk tiga dimensi } \\
\text { beserta tombol putar, } \\
\text { home, dan informasi. }\end{array}$ & $\begin{array}{l}{[\sqrt{ }] \text { berhasil }[]} \\
\text { tidak berhasil }\end{array}$ \\
\hline
\end{tabular}

Pengujian aplikasi AR Furniture dengan jenis pengujian fungsional berhasil dilakukan. Berdasarkan pengujian dengan metode black box, maka menghasilkan kesimpulan bahwa aplikasi AR Furniture dapat berhasil dijalankan sesuai dengan desain dan tujuan dan hasil yang direncanakan. Fitur-fitur maupun menu yang terdapat pada aplikasi berfungsi dengan baik. Keenam Marker dapat terdeteksi, sehingga objek tiga dimensi dari objek Furniture berhasil ditampilkan. Fungsionalitas dari aplikasi ini telah sesuai dengan perancangan.

\section{E.3. Pengujian Marker}

Pengujian pada marker dilakukan untuk mengetahui bagaimana marker dapat dideteksi oleh kamera pada teknologi Augmented Reality dan adakah faktor yang mempengaruhinya. Marker memiliki fungsi yang penting karena aplikasi AR Furniture menggunakan metode marker based. Sehingga marker harus dapat dikenali oleh kamera AR dengan mudah. Pada penelitian ini, penulis mencoba beberapa pengujian terhadap marker dengan menggunakan brosur AR, diantaranya sebagai berikut:

\section{E.4. Pengujian Jarak terhadap marker}

Proses pengujian dilakukan dengan range sudut kemiringan antara $0^{\circ}$ dan dengan jarak $5 \mathrm{~cm}, 10 \mathrm{~cm}, 15 \mathrm{~cm}, 20 \mathrm{~cm}, 25 \mathrm{~cm}$, dan $30 \mathrm{~cm}$. Hasil pengujian jarak terhadap intensitas cahaya di luar ruangan dditampilkan pada Tabel 3

Tabel 3 Hasil Pengujian Jarak

\begin{tabular}{|c|c|c|c|c|c|c|}
\hline \multirow{2}{*}{$\begin{array}{c}\text { Uji } \\
\text { Marker }\end{array}$} & \multicolumn{6}{|c|}{ Jarak Cm } \\
\cline { 2 - 7 } & 5 & 10 & 15 & 20 & 25 & 30 \\
\hline
\end{tabular}




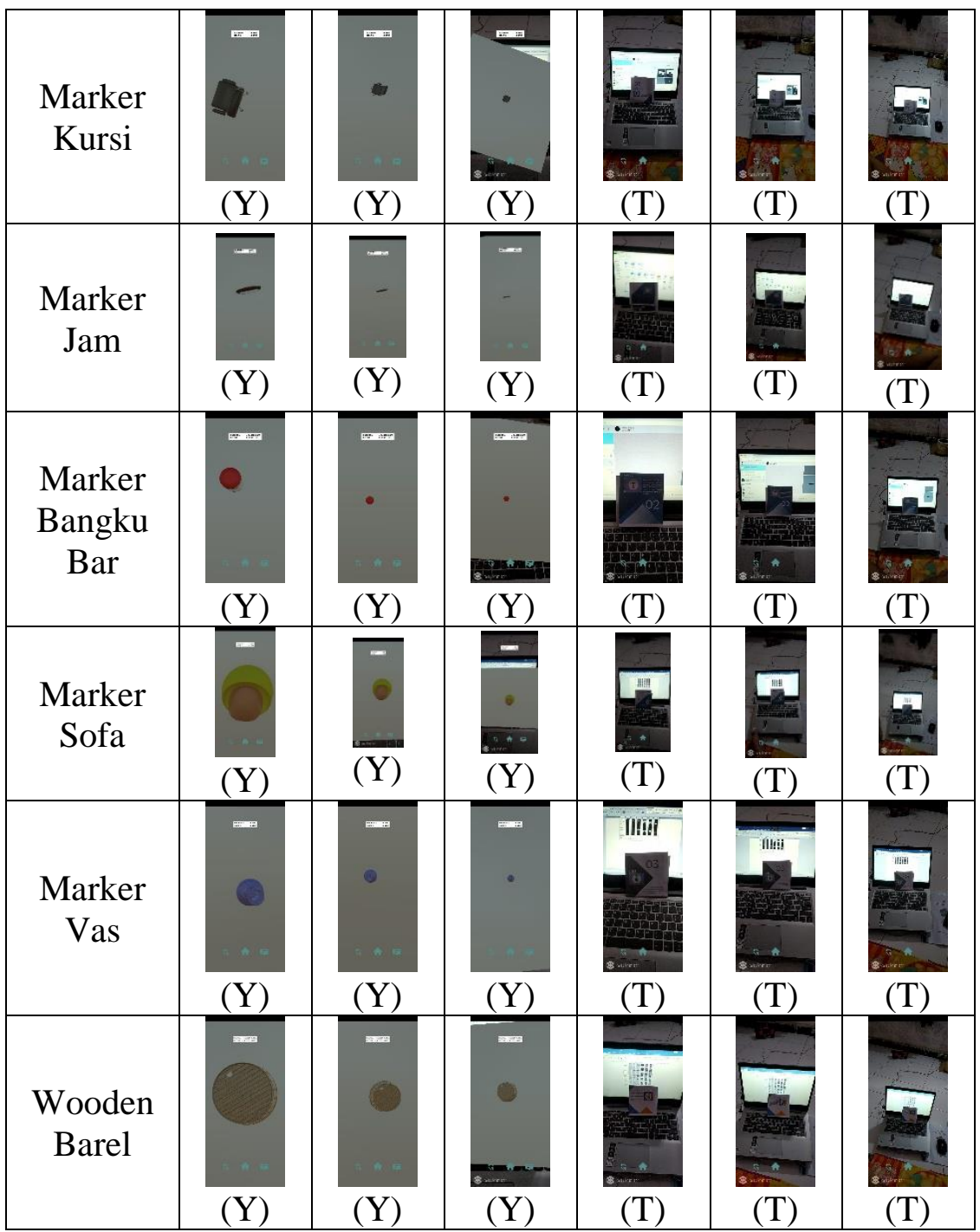

Keterangan: $(\mathrm{Y})$ : Ya Terdeteksi $(\mathrm{T})$ : Tidak Terdeteksi

Hasil dari pengujian jarak yaitu marker hanya dapat terbaca pada jarak $10 \mathrm{~cm}$ dan 15 $\mathrm{cm}$. Sedangkan pada jarak $5 \mathrm{~cm}, 20 \mathrm{~cm}, 25 \mathrm{~cm}$ dan $30 \mathrm{~cm}$ objek 3D tidak dapat terdeteksi. Sehingga disimpulkan bahwa jarak pembacaan marker yaitu minimum $10 \mathrm{~cm}$ dan maksimum $15 \mathrm{~cm}$.

\section{E.4. Pengaruh Sudut Kemiringan}

Setelah melakukan pengujian berdasarkan intensitas cahaya, maka dilakukan pengujian berdasarkan sudut kemiringan dalam pemindaian marker. Pada pengujian ini dilakukan dengan tujuan mengetahui seberapa pengaruh sudut kemiringan marker terhadap proses pendeteksian marker. Pengujian ini menggunakan pencahayaan sinar matahari dengan jarak kamera AR terhadap marker sejauh $15 \mathrm{~cm}$.

Pemilihan jarak didapatkan dari salah satu hasil pengujian sebelumnya yang menyatakan bahwa jarak $15 \mathrm{~cm}$ dapat memunculkan objek 3D. Penulis mencoba pengujian dengan sudut 
kemiringan $0^{\circ}, 15^{\circ}, 30^{\circ}, 45^{\circ}, 60^{\circ}, 75^{\circ}$ dan $90^{\circ}$. Hasil pengujian sudut kemiringan terhadap pemindaian marker ditampilkan pada Tabel 4

Tabel 4 Hasil Pengujian Sudut Kemiringan Marker

\begin{tabular}{|c|c|c|c|c|c|c|c|}
\hline Marker & & & udut & ringa & irker & & \\
\hline Uji & $0^{\circ}$ & $15^{\circ}$ & $30^{\circ}$ & $45^{\circ}$ & $60^{\circ}$ & $75^{\circ}$ & $90^{\circ}$ \\
\hline $\begin{array}{c}\text { Marker } \\
\text { Kursi }\end{array}$ & 0 & & I) & d & d & & \\
\hline $\begin{array}{c}\text { Marker } \\
\text { Jam }\end{array}$ & - & 0 & 0 & (1) & & & \\
\hline $\begin{array}{c}\text { Marker } \\
\text { Sofa }\end{array}$ & 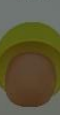 & & & & & & \\
\hline $\begin{array}{c}\text { Marker } \\
\text { Bangku } \\
\text { Bar }\end{array}$ & 0 & 9 & 9 & & & & \\
\hline $\begin{array}{c}\text { Marker } \\
\text { Vas }\end{array}$ & 0 & 8 & 3 & 3 & 8 & & \\
\hline $\begin{array}{c}\text { Marker } \\
\text { Wooden } \\
\text { Barel }\end{array}$ & & & & & & & \\
\hline
\end{tabular}

Hasil dari pengujian aplikasi berdasarkan sudut kemiringan pembacaan marker dengan sudut kemiringan $0^{\circ}, 15^{\circ}, 30^{\circ}, 45^{\circ}, 60^{\circ}, 75^{\circ}$, dan $90^{\circ}$ yaitu toleransi kemiringan pembacaan marker hanya berkisar pada $0^{\circ}$ hingga $75^{\circ}$. Sedangkan pada sudut kemiringan $90^{\circ}$ objek $3 \mathrm{D}$ tidak terdeteksi.

\section{KESIMPULAN}

Berdasarkan hasil penelitian, pengujian serta pembahasan mengenai aplikasi furniture augmented reality kesimpulan adalah :

1. Telah dihasilkan aplikasi AR Furniture yang menerapkan teknologi Augmented Reality berbasis android untuk memberikan pengetahuan dan pengenalan bagi wisatawan mengenai objek furniture dengan dukungan brosur AR untuk memindai. 
Prosiding The 1st National Conference on Applied Business, Education, \& Technology (NCABET)"

Unversitas Bina Bangsa 2021

DOI Article : 10.46306/ncabet.v1i1.6

2. Dalam menggunakan aplikasi, user perlu memperhatikan saat proses pendeteksian marker pada metode marker based, yaitu jarak antara marker dengan kamera , penerangan ruangan (intensitas pencahayaan) dan sudut kemiringan dalam proses pembacaan marker

3. Penerapan teknologi augmented reality berjalan sesuai dengan perancangan yaitu dapat memproyeksikan objek 2D berupa foto objek Furniture objek 3D secara lebih nyata

4. Proses memindai market dapat terdeteksi selama proses memindai tepat mengarah pada market. Hasil pengujian proses memindai tidak harus presisi tepat $100 \%$ pada gambar. Proses memindai dapat mendeteksi selama marker terdeteksi oleh kamera.

\section{DAFTAR PUSTAKA}

Adam Sinicky. (2019). Unity Untuk Pengembangan Game Android: Panduan Lengkap Untuk Desain, Pengembangan Hingga Pemasaran Game. Penerbit Andi.

Adiko, H. S. S. (2019). Penggunaan Media Pembelajaran Berbasis Ict (Information Communications Technologies) Dalam Meningkatkan Motivasi Belajar Peserta Didik. Akademika: Jurnal Ilmiah Media Publikasi Ilmu Pengetahuan Dan Teknologi, 7(2), 67. https://doi.org/10.31314/akademika.v7i2.312

Ambaryani, \& Airlanda, G. S. (2017). Pengembangan Media Komik Untuk Efektifitas Dan Meningkatkan Hasil Belajar. Jurnal Pendidikan Surya Edukasi, 3(1), 19-28.

Andriyani, F., \& Kusmariyatni, N. N. (2019). Pengaruh Media Komik Berwarna terhadap Hasil Belajar IPA Siswa. Jurnal Pedagogi Dan Pembelajaran, 2(3), 341. https://doi.org/10.23887/jp2.v2i3.19282

Azhariadi, Desmaniar, I., \& Geni, Z. L. (2019). Pembelajaran Berbasis Teknologi Informasi Dan Komunikasi (Tik) Di Daerah Terpencil. PROSIDING SEMINAR NASIONAL PENDIDIKAN PROGRAM PASCASARJANA UNIVERSITAS PGRI PALEMBANG, 7888. https://jurnal.univpgri-palembang.ac.id

Candra, F. A. (2020). Pengembangan Media Pembelajaran Tematik Berbasis TIK Di Sekolah Dasar. Prosiding Seminar Nasional PBSI-III, 3, 115-131. http://digilib.unimed.ac.id/id/eprint/41228

Eva, R., Sumantri, M. S., \& Winarsih, M. (2020). Media Pembelajaran Abad 21: Komik Digital Untuk Siswa Sekolah Dasar. Prosiding Seminar Dan ..., 1-8. http://journal.unj.ac.id/unj/index.php/psdpd/article/view/17744

Fadhli, M. (2015). Pengembangan Media Pembelajaran Berbasis Video Kelas Iv Sekolah Dasar. Jurnal Dimensi Pendidikan Dan Pembelajaran, 3(1), 24-29. https://doi.org/10.24269/dpp.v3i1.157

Grubert, J. (2013). Augmented Reality for Android Application Development. Packt Publishing.

Irnawati, O., \& Listianto, G. B. A. (2018). Metode Rapid Application Development (RAD) pada Perancangan Website Inventory PT. SARANA ABADI MAKMUR BERSAMA 
(S.A.M.B) JAKARTA. Evolusi : Jurnal Sains Dan Manajemen, 6(2), 12-18. https://doi.org/10.31294/evolusi.v6i2.4414

Ismayani, A. (2020). Membuat Sendiri Aplikasi Augmented Reality. Elex Media Komputindo.

Mardhatillah. (2016). Pengembangan Media Pembelajaran Interaktif Berbasis Tik (Teknologi Informasi Dan Komunikasi) Pada Materi Teks Narasi Di Kelas Iv Sd/Mi. Jurnal Bina Gogik, 2(2), 10-25.

Mukti, F. D. (2019). Pengembangan Media Pembelajaran Augmented Reality (AR) di Kelas V MI Wahid Hasyim. ELEMENTARY: Islamic Teacher Journal, 7(2), 299. https://doi.org/10.21043/elementary.v7i2.6351

Oktaviani, Y., Lusa, H., \& Noperman, F. (2020). Pengaruh Augmented Reality sebagai Media Pembelajaran terhadap Minat Belajar Siswa Mata Pelajaran IPA SD Kota Bengkulu. JURIDIKDAS: Jurnal Riset Pendidikan Dasar, 2(3), 202-208. https://doi.org/10.33369/juridikdas.2.3.202-208

Pamoedji, A. K., Maryuni, \& Sanjaya, R. (2017). Mudah Membuat Game Augmented Reality $(A R)$ dan Virtual Reality (VR) dengan Unity 3D. Elex Media Komputindo.

Ponza, P. J. R., Jampel, I. N., \& Sudarma, I. K. (2018). Pengembangan Media Video Animasi pada Pembelajaran Siswa Kelas IV di Sekolah Dasar. Jurnal Edutech Undiksha, 6(1), 919.

Rahmawati, A. (2020). PENERAPAN METODE RAPID APPLICATION DEVELOPMENT (RAD) DALAM PENGEMBANGAN SISTEM INFORMASI DATA TOKOi. Sitech (JURNAL SISTEM INFORMASI DAN TENOLOG), 3(2), 95-102.

Sholeh, M., Fatkhiyah, E., \& Bismin. (2021). Development of Augmented Reality-Based Animal Recognition Application Using Unity. 1st International Conference In Education, Science And Technology, 1, 147-155.

Sri Mulyani. (2016). Metode Analisis dan Perancangan Sistem. Abdi Sistematika.

Sunami, M. A., \& Aslam. (2021). Pengaruh Penggunaan Media Pembelajaran Video Animasi Berbasis Zoom Meeting terhadap Minat dan Hasil Belajar IPA Siswa Sekolah Dasar. Jurnal Basicedu, 5(2), 1060-1066.

Widiyasanti, M., Proketen, S. D., \& Yogyakarta, N. (2018). Pengembangan Media Video Animasi Untuk Meningkatkan Motivasi Belajar Dan Karakter Tanggung Jawab Siswa Kelas V. Jurnal Pendidikan Karakter, 8(1), 1-16. https://doi.org/10.21831/jpk.v8i1.21489 